\title{
Bernard Barbiche,Christian Sorrel (éd.), La Jeunesse étudiante chrétienne (1929-2009)
}

Lyon, Chrétiens et sociétés, $\mathrm{n}^{\circ} 12,2011,283$ p.

Frédéric Gugelot

\section{(2) OpenEdition}

\section{Journals}

Édition électronique

URL : http://journals.openedition.org/assr/23430

DOI : $10.4000 /$ assr. 23430

ISSN : $1777-5825$

\section{Éditeur}

Éditions de l'EHESS

Édition imprimée

Date de publication : 31 décembre 2011

Pagination : 103

ISBN : 9782713223273

ISSN : 0335-5985

\section{Référence électronique}

Frédéric Gugelot, «Bernard Barbiche,Christian Sorrel (éd.), La Jeunesse étudiante chrétienne (1929-2009) », Archives de sciences sociales des religions [En ligne], 156 | octobre-décembre 2011, document 156-12, mis en ligne le 14 février 2012, consulté le 21 septembre 2020. URL : http:// journals.openedition.org/assr/23430; DOI : https://doi.org/10.4000/assr.23430

Ce document a été généré automatiquement le 21 septembre 2020.

(C) Archives de sciences sociales des religions 


\section{Bernard Barbiche, Christian Sorrel (éd.), La Jeunesse étudiante chrétienne (1929-2009)}

Lyon, Chrétiens et sociétés, $\mathrm{n}^{\circ} 12,2011,283$ p.

\section{Frédéric Gugelot}

\section{RÉFÉRENCE}

Bernard BARBICHE,Christian SORREL (éd.), La Jeunesse étudiante chrétienne, (1929-2009), Lyon, Chrétiens et sociétés, $n^{\circ} 12,2011,283$ p.

1 Le dépôt des archives de la JEC au Centre national des archives de l'Église de France justifiait cette journée d'études où se mêlent travaux d'historiens et témoignages de militants. Le bilan historique de la JEC s'articule autour de quatre articles disposés chronologiquement.

2 Dès l'origine, ce mouvement de jeunesse dispose d'un terreau fertile (Gérard Cholvy). $\mathrm{Au} \mathrm{XIX}{ }^{e}$ siècle, l'Église catholique offre à la jeunesse nombre d'organisations, de mouvements qui permettent de vivre et de raffermir sa foi. Catholiques, et protestants note l'auteur, ont bien conscience des difficultés lors de l'adolescence à pérenniser une fidélité religieuse. Réunir de jeunes croyants autour d'un projet commun apparaît alors comme une solution (à l'exemple de la Société de Saint-Vincent-de-Paul). Viser les élites semble aussi particulièrement efficace (ACJF...) d'autant que l'existence même de la JEC met à mal le schéma classique du détachement des élites. Néanmoins, ces mouvements de laïcs entrent parfois en tension avec la hiérarchie et les aumôniers, surtout quand se développe le modèle de l'Action catholique.

3 L'article suivant (Christophe Roucou) rappelle l'existence d'un «courant jéciste» avant même la naissance effective du mouvement tant les essais d'un apostolat étudiant se multiplient dans les années 1920. À partir de sa naissance en 1929, l'histoire mouvementée du mouvement n'est qu'une suite de crises, de difficultés et 
d'interrogations. Comment pourrait-il en être autrement alors que la jeunesse scolaire et universitaire n'est pas par définition un milieu homogène et stable.

4 Au sortir de la guerre, la JEC semble connaître un moment de réelle réussite. Pour Bernard Giroux, ce succès de la Libération aux années 1960 s'explique par une cohérence entre des fondements théologiques promus et une conception globale du monde qui permet aux militants de concilier appartenance à l'Église catholique et inscription dans la modernité. L'argument est convaincant, mais l'expression de l'auteur, évoquant «un écosystème», nous semble malheureuse. Les débats ne cessent pas pour autant.

5 La radicalisation politique de la JEC, après la crise de 1965, apparaît alors comme une tentative de répondre aux crises incessantes du mouvement. Mais si les tensions apparaissent si fécondes dans les années 1950, elles sont devenues mortifères à partir des années 1960 (Vincent Soulage). La JEC s'inscrit dans une position contestataire de la société et de l'Église, qui aspire à rester en prise avec la jeunesse. Le mouvement forme et fournit alors des générations de militants qui irriguent largement la gauche mais les effectifs chutent fortement.

6 Deux témoignages de générations différentes offrent de réelles perspectives pour éclairer les propositions des historiens. Je retiendrai deux points du témoignage de l'historien et ancien jéciste Yves-Marie Hilaire: l'importance de l'amitié au sein de mouvements tel que la JEC et son rôle dans la formation des élites (ici les exemples cités sont tous universitaires). On retrouve cet aspect formateur dans celui d'une récente dirigeante nationale, Catherine Thieuw-Longevialle (qui évoque l'apport de confiance en soi, d'élargissement des horizons, de constitution de réseaux que fut pour elle le mouvement). Une fois de plus, la définition de la mission de la JEC continue de peser sur les survivants du mouvement, l'important et inévitable «turn-over» des cadres, le vieillissement des membres et leur entrée dans la vie active les éloignant naturellement de leur engagement de jeunesse. Facteurs externes (les crises successives, la politisation du mouvement dans les années 1970, une pastorale trop centrée sur les «milieux», les évolutions sociologiques qui mêlent crise de l'engagement et poids des loisirs et de la sécularisation...) et effets internes (l'isolement de la JEC, le choix des grands rassemblements pastoraux tels les JMJ) se conjuguent à la rareté des aumôniers, qui assurait avant la continuité du mouvement, pour expliquer le «crépuscule» de la JEC. L'ensemble est conclu par une excellente synthèse de Jacques Prévotat.

7 L'ouvrage s'accompagne d'un dictionnaire biographique de 1260 responsables nationaux et aumôniers de la JEC de 1929 à 1975, réalisé par Bernard Giroux, qui en fait un outil de travail indispensable même si certaines notices, très courtes, méritent à l'avenir d'être complétées. Cette journée d'étude livre donc une base de recherche incontournable sur la JEC qui fait espérer bien d'autres travaux. 